\title{
Multilingual Ability as Driving Force behind Global Citizenship: A Preliminary Overview from East Asia
}

\author{
Monica Dwiyanti \\ University of Indonesia \\ Email: monica.dwiyanti@ui.ac.id
}

http://dx.doi.org/10.18415/ijmmu.v5i5.381

\begin{abstract}
Using globalisation as starting point, this writing sees that old conception about identity and ingroup feelings have not disappeared despite increasing transnational relations. On the contrary, they often collide with new values and identities that come with globalisation. Amidst these problems, the notions of global citizenship and intercultural understanding attempt to provide middle ground. However, the discussion on global citizenship and intercultural understanding is not entirely complete without multilingual ability. Thus, this writing argues that multilingual ability is an essential driving force behind global citizenship and intercultural understanding. Two reasons are presented to support this main argument: 1) multilingual ability enables people from different nations to interact and communicate; and 2) the process of learning second or third language provides opportunities for learners to understand cultures of the native speakers. The article is structured as follow: 1) introduction; 2) global citizenship and intercultural understanding; 3) the role of multilingual ability; and 4) conclusion. To enrich the discussion, I conducted interviews with 5 students with 4 different nationalities. The interviews highlight the role of multilingual ability to enable communication and to build intercultural understanding.
\end{abstract}

Keywords: Multilingual Ability; Global Citizenship; Intercultural Understanding; Globalisation

\section{Introduction}

Globalisation has been enabling transnational relations. In a broad term, globalisation is commonly associated with the questions of borders, issues of governance, economy, identity, and community (Scholte., 1997). Various values and identities blend together in the era of globalisation because of transnational communication. However, it does not mean that the old conception of identity and in-group feelings have disappeared. On the contrary, they often collide with new values and identities that come enabled by globalisation. This realisation has long been observed in previous literatures.

In relations with cultures and identity, this article agrees with Eriksen's (2010) conception about globalisation as a dualistic process. Globalisation operates in a dialectical negation: 1) it shrinks the world by enabling cross-boundaries communication but it expands the world by affirming differences; 2) globalisation is centripetal because of its ability to connect people from all over the world but it is also centrifugal because it reaffirms local uniqueness; 3) globalisation fosters cosmopolitanism and 
fundamentalism at the same time. The third point cannot be more relevant and real in our world today. On one hand, globalisation spreads the ideas that all people are in the same boat and thus have to live together. On the other hand, globalisation opens a space of fundamentalism, missionary universalism, and parochial localism. The main reason behind this is because globalisation inevitably forms a sense of alienation; globalisation can be seen as a threat to identity and political sovereignty (Eriksen., 2010). The similar sentiment is echoed by Castells. The age of globalisation has witnessed the resurgence of strong nationalist principles. Identity on the basis of nationality is reconstructed and is used against the alien (Castells., 2010).

While globalisation provides new opportunities for people to connect to each other, alienation and discrimination examples are abundant. One of the most prominent examples of alienation is occurring in Myanmar. As it is widely known, there is ongoing humanitarian crisis experienced by Rohingya in Myanmar. The alienation of Rohingya is most obvious when their citizenship was taken away by law enacted in 1982. Currently, allegations of genocide against Rohingya came to the surface. Rohingya experiences discriminatory deprivation of basic rights, limited access to medicine and food, and hate speech (Southwick., 2015).

Racial tension also takes place in Indonesia; between Chinese-Indonesians and indigenous Indonesians. Although this racial tension has root in Dutch colonial (Walujono., 2014), it is still relevant today. Protest against Jakarta's governor Basuki Tjahaja Purnama is case in point. He proved that Chinese-Indonesian can achieve high office position yet anti-Ahok protest calls of reconsideration if minority of Chinese-Indonesian has actually been accepted (Holmes., 2017).

\section{Research Question}

Amidst all these longstanding problems, the notions of global citizenship, intercultural understanding, and multilingual ability attempt to provide middle ground. It is then essential to ask how multilingual ability can foster global citizenship and intercultural understanding.

\section{Methodology}

This research is qualitative in nature. As Leavy (2014) describes it, qualitative research is defined as a means to learn about social reality. It is employed so that a social phenomenon can be explored, described, or explained. In other words, qualitative research is capable of creating depth understanding on some aspects of social life. As such, research participants are seen as co-creators and knowledge bearers. Based on this, qualitative research is apt to be used since the research question seeks to describe how multilingual ability can foster global citizenship and intercultural understanding.

Among wide arrays of data collection methods, this article used semi-structured interview mainly because it can explore qualitative aspects of human experience and interaction (Brinkmann., 2014). If we see structured interview and unstructured interview as two poles, semi-structured interview is somewhere in the middle. Semi-structured interview gives space for the interviewees to express the matters that are important for them and at the same time allows interviewer to have say in focusing the conversation to the direction which is essential to the research.

The research participants were chosen through non-probability sampling, namely purposive sampling in which units are selected in order to reflect certain features (Ritchie., Lewis., \& Elam., 2003). I conducted interviews with 5 students with 4 different nationalities, namely Bruneian, Filipino, Indonesian, and Japanese. All of the interviewees have multilingual ability and have ever been involved 
in international events including but not limited to international conference, international competition, and student exchange program. Aforementioned nationalities were chosen to get the preliminary overview of experiences in East Asia. As the number of sample in this research is small, generalization can only be done by referring to other similar researches.

\section{Global Citizenship and Intercultural Understanding}

The term global citizenship does not have a single definition (Reysen., 2013). Reysen defines global citizenship as "awareness, caring, and embracing cultural diversity while promoting social justice and sustainability, coupled with a sense of responsibility to act". In this sense, global citizenship is an attitude or mind-set. One's self-identification as global citizen is commonly associated with intergroup empathy, valuing diversity, environmental sustainability, intergroup helping, and responsibility to act (Reysen., 2013).

Another insight on global citizenship is found in Linklater's writing. The conception of global citizenship or cosmopolitan citizen are rooted in Kantian tradition. Kantian tradition defines world citizenship as obligations to care about the future of the whole human race. Originally Kant argues that ius cosmopoliticum commands all humans to show hospitality to strangers because they are all citizens of a universal state of humanity. The ideas of global citizenship challenge orthodox conception of citizenship which contends that citizenship is inseparable from territoriality, sovereignty, and shared nationality (Linklater., 1998).

The second idea that attempts to provide middle ground is intercultural understanding. As globalisation facilitates interaction of people coming from various background, diversity is inevitable. Thus, intercultural understanding or intercultural competence is imperative. Themes about intercultural competence are mostly framed in the educational practises. It indicates that education indeed plays a huge role in assisting individuals to level up their cross-cultural sensitivity and intercultural communication. Furthermore, intercultural competence can decrease prejudice against others (King., Perez., \& Shim., 2013). Prejudice and stereotypes are not new vocabularies in intercultural differences. Young describes stereotypes as "pictures in our heads which may be definite mental images or verbal characterizations. They are shortcuts to conclusions" (Young., 1932).

This writing believes that global citizenship and intercultural understanding are closely intertwined in several ways. First, in order to have an attitude described in Reysen's (2013) definition of global citizenship-awareness, caring, and embracing cultural diversity-one has to possess intercultural understanding. Echoing this point, Trede, Bowles, \& Bridges (2013) mentioned that intercultural competence and global citizenship are closely aligned since global citizenship is associated with social responsibility, global equality, and human rights. All of these align well with the ideas of intercultural competence. Embracing cultural diversity can only happen if one understands the virtues in different cultures. Such understanding will foster tolerance; it makes them understand that there are other ways and perspectives besides their own. In short, intercultural understanding is the first step before achieving global citizenship. Second, intercultural understanding can potentially prevent individuals to be trapped in fundamentalism, missionary universalism, and parochial localism.

\section{The Role of Multilingual Ability}

The concept of multilingual ability helps us in nurturing our understanding about global citizenship and intercultural understanding. Multilingual ability or multilingualism is "the ability to speak, at some level, more than one language" (Edwards., 1994). This writing argues that multilingual ability 
is an essential driving force behind global citizenship and intercultural understanding. There are several reasons why multilingual is a powerful driving force behind global citizenship and intercultural understanding. First, multilingual ability enables people from different nations to interact and communicate to each other. Second, the process of learning second or third language provides opportunities for learners to understand cultures of the native speakers.

As mentioned earlier, I conducted interviews with 5 students with 4 different nationalities, namely Bruneian, Filipino, Indonesian, and Japanese. The first reason why multilingual ability is imperative is that because it serves as medium for interaction and communication. Such interaction and communication are expected to help individuals gaining intercultural competence and thus fostering global citizenship. This is consistent with Edwards's ideas that languages can serve as aids for crossgroup understanding. It especially true for lingua francas which bridge different national groups and language communities (Edwards., 1994). This conceptual explanation is in line with students' experiences with multilingualism. The first student from the Philippines who speaks English, Tagalog, and Bisaya affirms that studying English allows her to communicate with people from different countries; English allows her to connect with them. The experience is most prominent when she joined international event with exchange students in her university. She also reveals that multilingual ability helps her to obtain intercultural understanding during those events. In relations with global citizenship, she perceives that multilingual ability is a crucial element because of two reasons: 1) it lessens the risk of misunderstanding; and 2) it broadens an individual's world view.

Another account from Bruneian student who happens to speak English, Malay, Tutong, and Dusun language demonstrates the role of multilingual ability in communication. Without an understanding about the others' language, reluctance to interact emerges. Referring to her experience of attending international exchange program, she explained that she would not even bother to talk to someone if she did not understand one's language. In addition, the second Filipino student who is able to speak English, Bisaya, Filipino, Mandarin, Korean, and Cantonese equally values the multilingual ability. Having participated in The Youth Assembly, she thinks that multilingual ability is very important to make individuals more sensitive and more knowledgeable on other cultures and how to respond them. Regarding global citizenship, she believes that language barrier is the most salient obstacle to build connection with people and multilingual ability can mitigate this.

The following part will explain the second reason how multilingual ability can nurture global citizenship and intercultural competence. The process of learning other languages offers avenue for learners to comprehend cultures of the native speakers. The point is reflected in Filipino student's experience. By learning Korean, she is able to recognize that Koreans in general like to get things fast because they are very fond of making shortcuts for long words. As she learns Korean through television shows and movies, she can learn slang words which do not usually appear in formal language education. This is not surprising as language contact and cultural contact are commonly the same thing. Interrelationships between language and speakers are undeniable (Edwards, 1994). In Jiang's words, language reflects culture, shaped by it, as well as influenced by it (Jiang, 2000).

A parallel perspective is expressed by Japanese student who deems English as a crucial medium to get to know similarities and differences of different cultures. English enables her to understand different social context between Japanese and Filipino like the expected behaviours on women and men. At a more practical level, English as a lingua franca helps her to navigate in group work involving students with diverse background. Lastly, student from Indonesia has the same opinion. According to her, multilingual ability is a powerful tool that can help her have better intercultural understanding. Intercultural understanding provides room for discussing trade and education, de-radicalisation, education, and tourism. In turn, intercultural understanding serves as a foundation for global citizenship where individuals share similarities at global level. 


\section{Conclusion}

As it is explained, the encounter between two or more different cultures is inevitable in the era of globalisation. This is where the concept of global citizenship, intercultural understanding, and multilingual ability take an important role. In sum, learning another language besides mother tongue does not only enable people to communicate with others but also facilitates them to understand the people in which the language is originated. It is especially valuable when discussing about global citizenship as we talk about embracing cultural diversity and caring about the future of the whole human race. Multilingual ability is essential because it serves as a medium for interaction and communication for people coming from different cultural backgrounds. It has the potential to expand the knowledge on how someone sees the world. According the students interviewed in this research, multilingual ability is especially valuable in international events where they have to engage with diverse counterparts. In addition, second or third language learning process provides room for learners to understand the native speakers' cultures. Some cultural traditions are not always visible during communication but their meaning is present in language and its structure. That being said, one has to be sensitive enough to see meaning behind language.

\section{References}

Brinkmann, S. (2014). Unstructured and Semi-Structured Interviewing. In Leavy, P (Ed.), The oxford handbook of qualitative research (p. 277-300). Oxford: Oxford University Press.

Castells, M. (2010). The Power of Identity. West Sussex: Blackwell Publishing Ltd.

Edwards, J. (1994). Multilingualism. London: Routledge.

Eriksen, T. H. (2010). Ethnicity and Nationalism. New York: Pluto Press.

Holmes, O. (2016, November 25). Jakarta's Violent Identity Crisis: Behind the Vilification of ChineseIndonesians. The Guardian. Retrieved from https://www.theguardian.com.

Jiang, W. (2000). The Relationship Between Culture and Language. ELT Journal, 54(4): 328-334.

King, P. M., Perez, R. J., \& Shim, W.-J. (2013). How College Students Experience Intercultural Learning: Key Features and Approaches. Journal of Diversity in Higher Education, 6(2): 69-83.

Leavy, P. The Oxford Handbook of Qualitative Research. (2014). Oxford: Oxford University Press.

Linklater, A. (1998). Cosmopolitan Citizenship. Citizenship Studies, 2(1): 23-41.

Reysen, S., \& Katzarska-Miller, Iva. (2013). A Model of Global Citizenship: Antecedents and Outcomes. International Journal of Psychology, 48(5): (2013), 858-870.

Ritchie, J., Lewis, J., \& Elam, G. (2003). Designing and Selecting Samples. In Ritchie, J. \& Lewis, J. (Eds.), Qualitative Research Practice: A guide for Social Science Students and Researchers (p. 77-108). London: Sage Publications Ltd.

Scholte, J.A. (1997). Global Capitalism and the State. International Affairs, 73(3): 427-452. 
Southwick, K. (2015). Preventing Mass Atrocities Against the Stateless Rohingya in Myanmar: a Call for Solutions. Journal of International Affairs, 68(2): 137-156.

Trede, F., Bowles, W., Bridges, D. (2013). Developing Intercultural Competence and Global Citizenship Through International Experiences: Academics' Perceptions. Intercultural Education, 24(5): (2013), 442-455.

Walujono, A. (2014). The Discrimination of the Ethnic Chinese in Indonesia and Perceptions of Nationality (Master's thesis). Scripps College, Claremont, CA.

Young, D. (1932). American Minority Peoples. New York: Harper and Brothers.

\section{Copyrights}

Copyright for this article is retained by the author(s), with first publication rights granted to the journal.

This is an open-access article distributed under the terms and conditions of the Creative Commons Attribution license (http://creativecommons.org/licenses/by/4.0/). 